\title{
From EFL classroom language to classroom lexicon: Importing formulaic story language into teacher talk
}

\begin{abstract}
This paper reports on a language activity carried out in an Italian University with student teachers attending a primary education course. The activity was designed to train them to use authentic children's picturebooks as a source for EFL language learning. It consisted of identifying and 'noticing' (Mackey 2006) multiword expressions and ready-made utterances in a number of authentic picturebooks and simulating instances of weaving the picturebook language into the fabric of daily classroom talk. Following the activity, the students wrote individual pieces of reflective writing describing their experience. Comments by student teachers assessed the use of picturebook-derived formulaic language on both their learning and perceived ability to teach English, and revealed much about their pedagogical perspectives on teacher talk. Results suggest that promoting the use of authentic and meaningful language in context can help student teachers conceive of classroom communication as lexicon (a shared communicative practice the rules of which are fully known only by a restricted community of speakers) rather than mere language-based interaction.
\end{abstract}

KEYWORDS: EFL teacher talk, formulaic language, repetition in the EFL classroom, classroom lexicon.

\section{INTRODUCTION}

This language activity took place during a series of university workshops on the uses of authentic picturebooks as a language-teaching tool in the EFL primary classroom. The focus was on oral retellings of picturebooks as a source of language learning for pupils and student teachers alike, particu- 
larly in regard to the expressive power of performance as a guide to meaning. The fundamental role that picturebook storytelling plays in language learning is widely recognised (Masoni 2018; 2019; Cameron 2001; Linse 2007; Dujmović 2006; Ellis \& Brewster 2014; Mourão 2016): stories contain highly contextualised language that provides the 'here and now' that children rely on for meaningful language acquisition, and performed narratives facilitate comprehension of word meaning as well as memorisation (Cabrera \& Martínez 2001). The fundamentally aural nature of picturebooks, which are meant to be read out loud and learned through repeated retellings, makes their language hard to forget, considering also the added power of frequently used rhyme, alliteration and rhythmic metrics. Likewise, illustrations, teacher's performance and concrete language guide the young learners towards meaning in ways that facilitate learners' autonomy and result in long-lasting and retrievable memory of language items. Besides, modern picturebooks contain language in use which children can transfer to other present and future real-life contexts. The majority of direct speech we find in picturebooks allows the listener to readily transfer utterances to daily speech: this live language (often represented by dialogues between adults and children) reflects contemporary native use and it therefore has the power to make EFL pupils part of a wider community of speakers and grant them access to the cultures of the target language (Masoni 2019). Cameron speaks of the need to aim for "dynamic congruence" with young learners, that is "choosing activities and content that are appropriate for the children's age and socio-cultural experience, and language that will grow with the children, in that, although some vocabulary will no longer be needed, most of the language will provide a useful base for more grown-up purposes" (Cameron 2001: $30-31)$. The language of picturebooks has the potential to last a long time and resurface when needed.

Yet, telling a story is not enough for children to pick up language through implicit learning mechanisms (and learn how to use it), nor are post-storytelling activities: "input without interaction is not sufficient for language acquisition" (Wray 2000: 468). Children need to be shown how to 'copy' and recycle the language of stories in daily talk, in order to fully appreciate its communicative power. Indeed, "the ability to make connections between texts and personal experience is vital for children's literacy learning" (Torr 2004: 182-183). The activity described here aimed to encourage student teachers to make use of 'text-to-life' intertextuality, with a view to showing children how the language of picturebooks could be imported into daily conversations to make sense of new real-life situations they had previously encountered only in fiction. 
Children's picturebooks are an equally important source of language for student teachers, since they represent an authentic window on the expressive world of children. In picturebooks, teachers can find the language of daily communicative events that occur in a child's life and that we take for granted in the L1, such as words of praise and encouragement. In a study by Hsiu-Chih (2008: 49), "teachers reported that from a linguistic aspect, they themselves also benefited from English picture story books", because, as one teacher in the study reveals, they "let me know how to explain a situation in simple English". Picturebooks can represent a sort of corpus of the language of and around children, from which student teachers can draw specific linguistic knowledge. The results of the activity described here suggest that the practice of extracting language from picturebooks can influence student teachers' perceptions of classroom communication, and turn mere languagebased exchanges into meaningful interactions based on collectively built (and negotiated) communicative knowledge, here defined as classroom lexicon.

\section{FROM PICTUREBOOKS TO CLASSROOM INTERACTION}

Research on the 'age factor' and the 'earlier is better' hypothesis (Mayo \& Lecumberri 2003; Muñoz 2006) contends that younger children do not necessarily learn more than older children in instructed foreign language learning (DeKeyser \& Larsen-Hall 2005; Muñoz 2014; Wray 2008). One critical variable in this respect is the amount of exposure to the foreign language (Rokita-Jaśkow \& Ellis 2019), deemed "insufficient for children to be able to make use of implicit learning mechanisms" (Muñoz 2006: 33), considering that these children generally do not make use of English outside the classroom.

While extending the time of exposure is usually not possible, we can act on the quality of what Krashen names the "teacher-talk that surrounds the exercises", and which he says "may be far more valuable than the exercise itself", because "we teach language best when we use it for what it was designed for: communication" (Krashen 1981: 10). If the language of picturebooks is also replicated in daily speech, we will get closer to providing what Muñoz (2006: 150) defines as "cumulative exposure and, above all, contact with high-quality input", which are deemed to be "predictors of learners' oral performance in the foreign language". Providing repetition that results in accumulation is necessary because "children are believed to rely fundamentally on a form of effortless implicit learning, consequent only to enormous amounts of exposure, a condition missing in the EFL context" (Muñoz 2006: 150). 
As well as aiming to train student teachers to augment children's exposure (by weaving quotes from stories presented in class into subsequent instances of teacher talk), this activity also aimed to maximise their future pupils' chances of defining meaning and eliminating ambiguity with regard to words and expressions learned during storytelling - because children often need "further social interactions" to fully grasp the meaning of words encountered in stories that could have ambiguous meaning, especially if abstract (Vogt \& Coumans 2003: 1).

At the same time, the language activity aimed to influence student teachers' pedagogical conception of meaningful EFL classroom talk in general. The thought of classroom talk - the fabric of simple utterances that in their L1 come naturally - often poses a problem to students in this course: some fear they might not be able to produce correct statements when not supported by a textbook, while others avoid taking this aspect into consideration, or think of classroom communication as a mere list of useful words and instructions. Yet, "meaningful teacher talk is central to the process of language learning" (Hall \& Verplaetse 2000: 5).

As Kourieos (2014: 291) points out, "the decade of the nineties has been characterized by a growing awareness of the role played by authentic communication and negotiation of meaning in effective language learning which has resulted in greater emphasis on the teacher's communicative competence in the target language". In this spirit, scholars engaged in defining the breadth of communicative expertise EFL teachers should possess, taking both language proficiency and pedagogical skills into consideration (Bondi \& Poppi 2011), at a time when teachers were specialising in EFL teaching. Yet, the present situation in many countries, including Italy, is one where generalist teachers teach English as well as other subjects, often with limited perceived or actual proficiency, and very little training in language teaching. The students who participated in this activity will be called upon to teach English as well as all other subjects, without majoring in EFL teaching. Many of them would rather not teach it, because they do not feel up to the task, especially in terms of productive skills.

For this reason, student teachers need help improving their "proficiency in productive domains" (Hsiu-Chih 2008: 49), and in particular domains that are specifically relevant to their future job (language of children and their imaginings), beyond generalised CEFR levels (Kourieos 2014) while at the same time reflecting on classroom talk as a shared practice where teacher and pupils come together to construct ever-changing meanings through the manipulation of language. I argue that children's picturebooks can provide important linguistic support for student teachers and enhance the pedagogical depth of their future teacher talk. 


\section{FORMULAIC LANGUAGE AND NOTICING}

Many of the expressions in picturebooks are formulaic in nature: they represent widespread ways of talking to and about children. In Wray's definition, a formulaic sequence is:

a sequence, continuous or discontinuous, of words or other meaning elements, which is, or appears to be, prefabricated: that is, stored and retrieved whole from memory at the time of use, rather than being subject to generation or analysis by the language grammar (Wray 1999: 214).

'Multiword strings', 'phraseological units', or 'multiword units' (Wray 2002), or 'prefabricated chunks', as Lewis et al. (1997) referred to them, are preferred ways of saying things which get to be defined as formulaic because they are characterised by internal exceptions to grammar rules, or simply because of frequency of use. As much as 50\% of the English language is deemed to be "formulaic in some way" (Coxhead 2018: 113). Research claims we should "lead learners to prefer those sequences which are the usual forms in a given speech community" (Wray 2000: 468), and pedagogical approaches to teaching formulaic language have been suggested and tested (Coxhead 2018; De Rycker 2014; Boers, Eyckmans, Kappel, Stengers \& Demecheleer 2006; Schmitt 2004; Schmitt \& Underwood 2004) ever since the importance of this feature of language for language learning was first highlighted (Lewis et al. 1997).

Children spontaneously "learn in larger chunks" (Wray 2008: 264; Muñoz 2006): for this reason, teachers need to be able to identify formulaic language and expose children to as much authentic input as possible, for children to acquire phraseological units that they can transfer into active use. At the same time, adults too would benefit enormously from "the exploitation of formulaic material" (Wray 2008: 265), because "the advantage of learning language in larger chunks is that the irregularities are hidden inside, and the forms can become comfortable to say and use without agonising over choices of word and word-ending" (Wray 2008: 268). In general, as Boers et al. (2006: 247) explain, the "use of formulaic sequences can help learners come across as generally proficient speakers", and can therefore result in learners perceiving themselves as more proficient.

In order to partially address student teachers' perceived problems with production and allow them to experience a sense of authenticity through handling native-sounding language, the students on the course were encouraged to take a more formulaic approach to learning, as they could benefit from adopting a language-learning mode that temporarily reduces "processing effort" (Wray 1999: 215) and supplies them with more native-sounding 
language, while also helping them develop "a sense of what 'sounds right' [in English]", beyond rules (Wray 2000: 484).

A sense of 'what sounds right' can be developed also through conscious 'noticing' (Mackey 2006) of linguistic forms that appear frequently in native use. Classroom instruction needs to give particular emphasis "to the importance of phrase-noticing" (Boers et al. 2006: 249), thus "turning 'pedagogical-chunking' [i.e. drawing attention to and teaching of phraseological units] into a frequent classroom activity" (Boers et al. 2006: 250). In line with studies on pedagogical approaches to formulaic learning (Boers et al. 2006), during the workshops the students' attention was drawn to linguistic forms through 'noticing', as well as through explanations and discussions aimed at raising language awareness.

Children's picturebooks offer an important authentic source for 'pedagogical chunking', because they make abundant use of phraseological units which reflect daily use. Consider a simple utterance like "mind your head", which can be repeated many times in a day to a child. This phrase was shaped by usage. Incidentally, the simpler the utterance, the harder it might be to construct it from scratch. An L1 Italian speaker, for example, would hardly come up with "mind your head" as a translation for the Italian equivalent "attento alla testa", which students often spontaneously translate in more literal ways, such as "be careful of your head". "Mind your head" is a formulaic expression, a preferred way of conveying this message: one needs to be exposed to it in order to pick it up. This is the case for many expressions used around children in everyday talk: they need to be taken and learned as whole chunks. Unless socialised in this language, student teachers will find it hard to get to know these words, and very difficult to construct them out of lexical and grammatical knowledge.

\subsection{Memorising formulaic language for active use}

The recent upsurge of calls for replication experiments in formulaic language teaching (Coaxhead 2018) signifies that interest in pedagogical chunking is high and that much is being done to find the most effective ways of committing the results of noticing to memory (and most of all to ensure learners can retrieve and use phrases in appropriate contexts).

Boers et al. (2006) tested students' use of formulaic language, previously learned through noticing, in subsequent oral conversations. Results revealed that the students in the experimental group "outperformed their control peers (whose attention had not been drawn to formulaic language) mainly in the first half of the interview, i.e. the part of conversation that was based on 
the short text they had been asked to read as preparation for the interview" (Boers et al. 2006: 256). For this reason, they concluded that "evidence that experimental students might have built up a larger repertoire of formulaic sequences for active use than the control students is less convincing". Importantly, Boers et al. go on to argue that "[n]oticing may be a prerequisite for learning, but it does not necessarily guarantee the acquisition of every single element that gets noticed" and, more to the point, they claim that "[p]erhaps the noticing activities would need to be complemented by activities with greater mnemonic potential to bring about a big enough change in students' FS repertoires to be statistically measurable over such a relatively short time span" (Boers et al. 2006: 256).

In order to "provide greater mnemonic potential", the activity here presented aimed to make students think and visualise concrete and precise instances of classroom interaction where language could be used in situations that differed from those in the picturebooks and that did not represent instances of book-related talk (i.e. talking about the picturebook). Besides picturebooks, which student teachers on the course had learnt by heart naturally and effortlessly (thanks to their musicality), made the structures that had been acquired through noticing activities penetrate in the participants' minds to a deeper level.

Adopting a formulaic learning habit, for learners who are not immersed in the language, implies a certain degree of memorisation and requires meaningful repetition. Wray (2008: 264) reports on experiments in "extreme learning" in which adult learners were made to memorise native-like language they had some likelihood of using in interaction. In most cases, learners failed to reproduce what they had memorised and could not resist changing wording at the cost of making mistakes. Ding, on the other hand, analysed the relationship between some students' proficiency and their habit of memorising material from audios and videos of public speeches by native speakers. Apparently, the practice enabled them to "borrow collocations and sequences for productive uses" (Ding 2007: 277). Ding's study suggests that learning from performance, where voice and intonation confer special meaning upon talk, can facilitate future use in other contexts.

The need to memorise texts was discussed during the workshops. Students were encouraged to memorise stories for reasons to do with performance (i.e. maintaining rhythm during narration), and they were directed to YouTube videos of people giving dramatic readings of the stories employed in class. The activity here described took it for granted that the participants would know the story by heart and that this would facilitate the spontaneous retrieval of certain items of language in daily conversation, as often happens 
for lines of songs that are used to comment on life. This was not brainless memorisation. Memorisation was actually seen as a way of increasing expressive freedom in classroom talk.

\subsection{Copying and weaving}

It is important for teachers to reflect on the necessity to turn the sometimes-natural process of referring back to memorised material into a language-teaching practice: a kind of "weaving", which refers to "the moments in classroom lessons when explicit connections are made - by teacher or students - across one or another dimension of knowledge (Cazden 2006: 1). As Cazden points out, "[u]sually, weavings connect something that is already familiar with new curriculum content" (2006: 1). Teachers weave previous knowledge into new situations all the time. Intertextual references from text to talk, where talk is seen as oral text, are extremely frequent in meaningful teacher talk. Teachers refer back to previously read picturebooks to remind students of the meaning of words they encounter in other contexts (Hsui Chih 2008). Duff uses the term "hybridity" to describe the practice of teachers who weave references to pop culture into their classroom talk, as a means of co-producing meaning. "Recycling" of other speakers' utterances for various productive purposes, including humour, is children's preferred way of producing language, as detailed by Cekaite and Aronsson (2004). The concept of recycling is close to the idea of format tying, defined as "strategic use of the surface structures (such as phonological, syntactic, and semantic surface structures) of previous utterances through exact or elaborated repetition" (Koymen \& Kyratzis 2009: 202). Children use repetition "to accomplish a wide range of social acts and thereby progress in their pragmatic competence" (Moore 2011: 210). These mechanisms create "meaningful contexts for the acquisition of linguistic and pragmatic skills", while managing to "consolidate the classroom community" (Cekaite \& Aronsson 2004: 388).

When children are very young, however, caregivers use repetition to show them what to do with language patterns and rules (Schieffelin \& Ochs 1996): indeed, meaningful repetition, prompting and dialoguing are also strategies used by teachers, especially in the EFL classroom (Cabrera \& Martínez 2001; Forman 2012). As Moore observes, "an important part of becoming communicatively competent is learning how to manipulate the repetitive patterns of language in ways that are both original and intelligible, as well as when and where one may do so" (Moore 2011: 220). If the teacher weaves a wellknown sentence from a book into interaction, such as "It's time I hid" (The Gruffalo by Julia Donaldson), she can then later on transform it into more 
commonly used forms, such as "It's time we went / did / finished". This implies giving "specific evidence from other input that indicates how [multiword strings] can be changed" (Wray 2008: 263) and helping children on the way to autonomy, that will lead them to "diverge from [given forms] in creative and possibly innovative ways" (Moore 2011: 220).

Picturebooks are also powerful sources for linguistic importations into classroom talk via the social dimension of performance and storytelling. They represent a common pool of knowledge, built within the classroom during performances. While classroom talk infused with references to pop culture could represent what Duff defines as "an unequally accessible 'third space' for the class" and especially "for immigrant newcomers" (Duff 2004: 231), referring to authentic texts in the primary classroom goes in the opposite direction, that of community building, as this intertextuality draws on an internally built pool which is bound to be shared by all the members of the class and create a special classroom lexicon (I will return to this point in the conclusion). Classroom interaction that imports language from oral retellings of picturebooks somehow re-enacts the moment of performance (in itself a positively connotated moment in emotional terms) thus reinforcing community also through a process of collective remembering.

The kind of weaving we refer to here is very much influenced by performance. As shall be seen later, students were encouraged to repeat the utterances imported into talk with the exact voice and emphasis they employed when telling the story (at least for the first uses of the utterance outside the book). This practice, together with the use of emphatic gestures has the power to provide children with "the perceptual structure that can and does reduce ambiguity" (Zucow-Goldring 1996: 197), thus clarifying meaning even further.

\section{RESEARCH METHOD}

\subsection{The participants}

The participants were approximately 60 student teachers (divided in two groups) attending their fourth year of studies, and their ages ranged from 22 to 40+. Both groups received the same instructions. Their proficiency in English ranged from $\mathrm{A} 1+$ to $\mathrm{C} 1$, with the majority between $\mathrm{A} 2+$ and $\mathrm{B} 1$. The workshops comprised 16 teaching hours, divided into 4 sessions of 4 hours each, and spread over 2 months. Each session comprised 2 hours of lesson on the uses of storytelling and oral performances of picturebooks in the EFL classroom, and 2 hours of independent group work. The activity here 
described was carried out over the four meetings and took up approximately 6 of the 16 hours. At the end of the last meeting, the students were asked to write a brief piece of reflective writing in English about the experience of seeking language in picturebooks and the workshops in general.

What follows has been put together through tutor / researcher's classroom notes, as well as students' written records of noticing activities and simulations of instances of classroom communication which were submitted to the tutor / researcher at the end of the workshops.

\subsection{The data collection process}

As part of the workshops, the students were exposed to a variety of authentic picturebooks in English: this constituted course material for this language activity. In general, care was taken to choose picturebooks that are currently popular in English-speaking countries and contain language that could be readily used in everyday life. Examples reported in what follows come mainly from The Gruffalo by Julia Donaldson and The Tiger who Came to Tea by Judith Kerr, although students carried out the same kind of work on a number of other texts as well.

The activity was organised in 6 main phases, during which students worked in groups of 3 or 4 . In the first phase, the students were asked to discuss what they meant by classroom language and write down examples, in Italian, of what they envisaged would be useful sentences in the future EFL classroom. Interestingly, the vast majority of the groups listed sentences that could be classified as instructions and commands, such as alzatevi (Eng. stand up), or fate silenzio (Eng. be quiet).

The second phase introduced the concept of 'formulaic sequence' or 'prefabricated chunks'. The students had no prior experience with these terms and were not familiar with the notion that children tend to learn through large units of language. This phase of language awareness raised considerable interest in the students and led to much talk about how language works. The tutor / researcher than moved on to raising "learners' awareness of the pervasiveness of formulaic sequences in (English) language" (Boers et al. 2006: 250).

Following this introduction to formulaic language, in the second phase, the students were assigned a noticing activity whereby they combed the texts of a number of picturebooks in search of formulaic expressions. As Gozdawa-Gołębiowski and Opacki (2018: 134) point out, there is no real agreement on "the most efficient tools for identifying formulaic strings in any stretch of text". In this activity, we required the strings to be of some phraseological 
interest and have communicative power that could be transferred directly in the classroom. Formulaicity was related to the corpus of picturebooks used in class, whereby a string such as "deep dark wood" (The Gruffalo) was considered formulaic for classroom use, but would not figure as such in a general corpus of the English language. Yet, this and similar phrases possess great communicative power for children who would immediately perceive that they were imported from picturebooks. The students were able to identify all multiword expressions in the texts, as well as notice frequent collocations. Examples produced by the students in this phase included "Where are you going?", "I told you so", "There's no such thing as" (from The Gruffalo), and "I wonder who that can be" (from The Tiger Who Came to Tea). Picturebooks contain much formulaic language, because they reflect, and simultaneously aim to expose children to natural talk. Besides, the fact that these strings were highlighted by frequent repetition in these patterned picturebook tales facilitated the identification of formulaic expressions.

The third phase focussed on the appreciation of the communicative power of the language of picturebooks and identification of exportable language: student teachers were asked to select collocations and multiword strings that they believed could be used in daily conversations. Interestingly, the students deemed that all the phrases they had previously noticed and highlighted could be used in daily speech.

The fourth phase consisted of applying casual importation in context: the students were asked to actually visualise "situations in which there was a [...] likelihood of the memorised material being usable in the near future" (Wray 2008: 265), i.e. simulate moments in a hypothetical primary classroom they might teach in the future where those phrases could be used. They were required to describe these situations in writing, with annotations for each selected phrase. They were encouraged to use either verbatim quotation or recycling (i.e. adapting the expressions through linguistic manipulation), as long as the intertextual nature of the importation could still be clear to an audience of children. In this phase, the students produced a surprising number of entries ${ }^{1}$. Some constituted direct borrowings applied to contexts that were sometimes similar to and sometimes quite different from the contexts in which the picturebooks had presented them, such as:

- "Where are you going ..." (The Gruffalo): used when a child gets up and starts to leave the room,

- "I wonder who that can be" (The Tiger Who Came to Tea): used when someone knocks at the classroom door,

${ }^{1}$ All of the quotes are in the original English produced by the students. 
- "I know what we'll do. I've got a very good idea!" (The Tiger Who Came to Tea): used when suggesting something new to the class.

There were other, more creative recastings that introduced metaphorical use of language, such as:

- "I hear a hiss in the leaves ahead" (The Gruffalo), which was turned into "I hear a hiss in the classroom", when a child is whispering or chatting,

- "Quick as the wind" (The Gruffalo) was used by many to ask children to wrap up an activity, or to give permission to go to the toilet ("yes, you can, but quick as the wind").

In this spirit, in the fifth phase, the students were encouraged to move even farther away from direct borrowing, and employ metaphorical weaving, by thinking of creative ways of saying common things. Examples produced by the students include:

- "Goodbye little mouse" (The Gruffalo), which became "goodbye little mice" to take leave at the end of the day,

- "My favourite food is Gruffalo crumble" became "my favourite food is child crumble", as a humorous way of reprimanding children.

The more metaphorical the use of borrowing became, the more it produced humorous recastings reminiscent of the children's humorous recycling described by Cekaite and Aronsson (2004). Importantly, students were able to maintain strong links with the original picturebooks also when the wording was changed. Indeed, for EFL pupils to understand the humorous twist caused by the change of context, the phrases had to maintain their formulaic nature even if slightly changed for classroom purposes because "formulaicity must be recognized in creative expressions that have clearly been derived from prefabricated chunks" (Bell 2012: 190). In this context, however, there was also the possibility of recognising the link exclusively by means of performance cues, and voice in particular. A statement such as "I'm off" (The Gruffalo) cannot be recognised by wording alone, as it could apply to all sorts of texts. It needs to be imported by employing the voice of Fox in The Gruffalo. Also for this reason, students were exhorted to make the most of performance cues during importation, in order to provide perceptual support that was indispensable for the construction of meaning in new contexts.

In the final phase, the students were asked to go back to their Italian list of classroom language and see if any of the expressions from the picturebooks could be used to creatively translate some of their initial sentences: this could involve taking the original phrases out of context. The students engaged in this phase creatively and enjoyed participating in this activity. Examples included: 
- "Fate una fila che andiamo in giardino" (lit. "form a line, because we are going to the garden", which became "I'll lead the way, and you follow after" (The Gruffalo) or "you lead the way and I'll follow after",

- "Bambini, andiamo in giardino a fare ricreazione. Non correte!" (lit. "Children, let's go to the garden for our break. Don't run!"), which became "It's time I hid in the garden. Just walk behind me" (from The Gruffalo).

Furthermore, some students spontaneously produced instances where picturebooks were used to convey important messages to children, without actual importation. For example, a student hypothesised replying to a child who says non mi sento bene (Eng. I'm not feeling well) in the following manner: "Maybe last night you ate too much, like the very hungry caterpillar" (reference to The Very Hungry Caterpillar by Eric Carle). This picturebook was used to create a response in English, to a statement in Italian. If properly supported with body language, the child would perfectly understand this useful recasting connected with a beloved story. Students proved to be very autonomous and creative in the work of identifying useful language and imagining new contexts for its use.

The activity aimed to show students that meaningful communication could be achieved by borrowing effective expressions which had positive emotional connotations for the children and that picturebooks provided teachers with metaphorical and creative ways of saying ordinary things. Interestingly, the use of humour and allusion turned some of their more directive statements into gentler ways of saying the same thing. As the students noticed this shift, the activity was implemented through viewing Ofsted (Office for Standards in Education in Britain) videos of outstanding primary literacy teaching, during which students were encouraged to identify gentler turns of phrase, such as the use of "How about we stand up?", instead of the imperative "Stand up". This was also the occasion to talk about the use of "please", "thank you" and other expressions of politeness, in search of native-sounding ways to say ordinary things.

At the end of the activity, the students had a clearer idea of what it meant and implied to provide a language learning environment that was based on formulaic language and therefore much closer to children's natural way of acquiring language.

\subsection{Reflective writing: From classroom language to classroom lexicon}

One of the most notable and hoped-for consequences of this activity was its effect on the participants' concept of classroom language. Not only did they acquire new expressions and words that 'sounded right', they also 
changed their perception of what it meant to communicate in the classroom and how carefully chosen language could act on classroom atmosphere, as their pieces of individual reflective writing prove.

In order to write their pieces, each student was given some key points they could follow or discard, apart from the first point, which they were all required to answer. The structure was as follows: 1 . Define what classroom language means to you; 2. Write about your own personal experience of seeking language from picturebooks during these workshops; 3 . What's special, if anything, about the language of picturebooks?; 4 . What have you learned from the language of picturebooks?; 5 . Where can we find inspiration for classroom language?; 6. Can you see yourself using picturebooks in the EFL classroom in the future? This was done on the principle that "the posing of specific questions improves prospective teachers' abilities to reflect at varying levels" (Nesmith 2011:26). Most of the resulting pieces did not follow this outline but were more in the direction of a cohesive reflection. All pieces were very personal and enthusiastic in tone.

What stands out immediately is a shift in perception following the group work. Consider the following passages2:

- "My personal image of an EFL class changed thanks to this workshop. It feels like my world has somehow shifted a little. I used to think of classroom language as the words to name the objects of the classroom. Now, what I hear, when someone says "classroom language", is "what kind of atmosphere do you want to create in your class?"

- "At the beginning of this workshop I thought classroom language wouldn't have been a problem. After the lessons and the videos, I've changed my mind. Using the right classroom language in English is very important, and it's a new thing for us,"

The students' words prove that classroom language is no longer conceived of as a set of instructions; rather, it is language practice with the power of achieving actual communication built on shared knowledge. As prospective teachers looking to make a difference and adopt more inclusive teaching methods in their future practice, the students on the course welcomed as 'new' the idea that EFL teaching could be informed by inclusive and cooperative language practice. There is a clear sense that teaching and learning are intertwined, as the following excerpts prove:

- "Classroom language means to share knowledge and feel the language as something to discover together, something that is alive and that can be very enriching in different ways for everyone."

${ }^{2}$ All the pieces of reflective writing quoted in the article are in the original in English written by the students, and so are the fragments between quotation marks woven into the general text. 
- "To build a common classroom language means for me to build a stronger relationship between children and language."

- Classroom communication "is not only grammar or words, it means to me a way to create a bond, to communicate and have fun with children."

- It is "a language you can build with children in your own class."

The idea of community is pervasive: the word "common" figures in almost every piece. In this context classroom communication is seen as "a special language to say normal things" that enables teachers to create a "good and magic atmosphere", or, in even more powerful terms: "as a little, precious, common treasure for children and teacher, for the class as a community...". This is where classroom language turns into classroom lexicon, a language with enhanced communicative power that can be fully understood only by teacher and pupils. In this sense, the students describe a sort of restricted code in Bernstein's terms, "based on an extensive range of shared expectations", and "common assumptions" (Bernstein 1971: 146).

These comments reveal another fundamental aspect: this language is no longer artificial, on the contrary, it is "alive" and infused with the voices of others. Working with authentic material and language in use had a most positive effect on student teachers. They reported that picturebooks are "full of true English everyday language", which allows teachers and pupils alike to "feel much closer to the language, to feel that the English words are really used somewhere in the world, so you can also feel to be part in that culture"; and this is deemed "good for children but also for teachers because they can understand the real English culture!" The adjective "real", employed so frequently in the responses, reveals that the synchronicity of language in use made English sound like a more authentic language, actually spoken by someone. This is where another important shift took place, the students began to look at language as culture (Byram \& Kramsch 2008), which allowed them access to a wider community of speakers by means of their newly formed knowledge of more native-like language. Interestingly, one student remarked that "[picturebooks] are very useful to teach a foreign language and to know quickly some secrets about it". This sense of revelation surfaces also in other comments, such as: "I found many expressions that I didn't know and I am surprised, because they are easier than I thought"; "Discovering native English language through these picturebooks has been much more interesting" or "I was very impressed by discovering expressions that do not exist in Italian", and as one student sums up, "This is fascinating, because this is what knowing English means". There is a clear sense that drawing attention to preferred ways of saying simple things made the student feel in direct contact with those who speak the language every day. 
Indeed, most of them declared that "with books the learning is both for the teachers and for the students", which echoes comments gathered by Hsiu Chih (2008) and that "picturebooks will help me and the children use the foreign language freely and with pleasure". Freedom and pleasure in the use of the foreign language seem very positive achievements, especially if seen in connection with the idea, expressed by many students, that children's picturebooks can help them continue to learn language over time.

Thanks to picturebooks, classroom interaction acquired enhanced communicative power, equalling that of their L1: "Having the English classroom language means to me being able to express myself and to talk to my kids as I can do in Italian. It means that when I talk, they can learn". This is a very important result, especially when considering that more than one student remarked that, during the workshops, they "realised that building a classroom language could be a precious opportunity teaching English, but also Italian". Indeed, building a shared classroom language based on references to shared pools of knowledge appears to be a pedagogical instrument that allows students to use their pedagogical skills, as well as to perceive they have enhanced expressive efficacy in the EFL classroom. Children's picturebooks seem to be a most useful tool to open up channels of communication that student teachers could not envisage in the beginning, thus partly addressing their fears of producing English language from scratch.

\section{CONCLUSIONS}

The practice of making creative and metaphorical uses of language borrowed from picturebooks works in two apparently opposed, and yet closely intertwined, ways. On the one hand, it has the power to reinforce the internal community: the imagined EFL classroom becomes what anthropologist Edward Hall called high context - in which utterances rely on shared knowledge in order to be understood and not just on processing of each single word for its meaning (Hall 1989), and classroom language becomes shared lexicon (Duff 2004: 232): i.e. a way of using language that only teachers and children who have engaged in the performance of picturebooks in class can fully understand, because it is infused with more or less direct references to stories. From another perspective, however, the words in these picturebooks grant the class the right to be part of a wider community of English language speakers. These multiple communities merge in the classroom, as the voices of others help to create a new voice, which, despite being unique and peculiar to the classroom, possesses enhanced universal communicative power, because it speaks through authentic language in use. 
Interestingly, the shift in perception that led the students to conceive of classroom language as a shared lexicon is strictly dependent on the authentic materials the students analysed and on the emphasis that was placed on 'noticing' formulaic language during the workshops. The feeling reported by the students of having been made part of a native "secret" derives precisely from handling authentic language they refer to as "real": this drove them to conceive of new and exclusive ways of interacting in the classroom. Additionally, the process of weaving language in simulated instances of classroom talk allowed students to recognise the expressive power of the language of picturebooks and to see classroom talk as an important context for augmenting children's exposure to authentic language.

These results suggest that picturebooks can be a valuable teaching material aimed at training student teachers to identify and acquire formulaic language: they represent authentic input which is of particular interest to teachers, both for the language it contains and the themes it develops; and their musical nature endows them with an added mnemonic value, which is fundamental for successful retrieval of formulaic language in the context of conversation. Training student teachers to fully exploit the linguistic power of authentic picturebooks ,bears' to ,has' positive effects on their perceived ability to express themselves in the future EFL classroom. More research is needed to turn this activity into a possible teaching methodology for student teachers. A larger study with a control group on the model of Boers et al. (2006), where the control group is not led to notice chunks, would prove useful, and so would a study including post-activity testing, to verify retention and ability to use formulaic strings in other contexts.

Future avenues of research should try to establish how children respond to this practice and whether classroom talk infused with references to picturebooks can actually augment exposure in the primary EFL classroom in significant ways.

\section{REFERENCES}

Bell, N. (2012). Formulaic language, creativity, and language play in a second language. Annual Review of Applied Linguistics, 32, 189-205.

Bernstein, B. (1971). Class, codes and control: Theoretical studies towards a sociology of language. Vol.1. London: Routledge and Kegan Paul.

Boers, F. / Eyckmans, J. / Kappel, J. / Stengers, H. / Demecheleer, M. (2006). Formulaic sequences and perceived oral proficiency: Putting a lexical approach to the test. Language Teaching Research, 10 (3), 245-261.

Bondi, M. / Poppi, F. (2007). Devising a language certificate for primary school teachers of English. Profile Issues in Teachers' Professional Development, 8, 145-164. 
Byram, K. / Kramsch, C. (2008). Why is it so difficult to teach language as culture? The German Quarterly, 81 (1), 20-34.

Cabrera, M. P. / Martínez, P. B. (2001). The effects of repetition, comprehension checks, and gestures on primary school children in an EFL situation. ELT Journal, 55 (3), 281-288.

Cameron, L. (2001). Teaching languages to young learners. Cambridge: Cambridge University Press.

Cazden, C. B. (2006). Connected learning: "Weaving” in classroom lessons. Pedagogy in Practice 2006 Conference. Newcastle, New South Wales: University of Newcastle Press.

Cekaite, A. / Aronsson, K. (2004). Repetition and joking in children's second language conversations: Playful recyclings in an immersion classroom. Discourse Studies, 6, 373-392.

Coxhead, A. (2018). Replication research in pedagogical approaches to formulaic sequences: Jones \& Haywood (2004) and Alali \& Schmitt (2012). Language Teaching, 51, 113-123.

De Rycker, A. (2014). Encouraging collocational and colligational fluency: Pedagogical chunking, word and verb mapping, pause reading and other strategies. Journal for Interdisciplinary Research in Education (JIRE), 4 (1), 1-16.

DeKeyser, R. / Larson-Hall J. (2005). What does the Critical Period really mean? In J. F. Kroll / A. M. B. DeGroot (eds.), Handbook of bilingualism: Psycholinguistic perspectives (pp. 88-108). New York: Oxford University Press.

Ding, Y. (2007). Text memorization and imitation: The practices of successful Chinese learners of English. System, 35 (2), 271-280.

Duff, P. A. (2003). Intertextuality and hybrid discourses: The infusion of pop culture in educational discourse. Linguistics and Education, 14 (3-4), 231-276.

Dujmović, M. (2006). Storytelling as a method of EFL teaching. Metodički Obzori: Časopis Za Odgojno-Obrazovnu Teoriju i Praksu, 1 (1), 75-87.

Ellis, G. / Brewster, J. (2014). Tell it again!: The storytelling handbook for primary English language teachers. London: British Council.

Forman, R. (2012). Six functions of bilingual EFL teacher talk: Animating, translating, explaining, creating, prompting and dialoguing. RELC Journal, 43 (2), 239-253.

Gozdawa-Gołębiowski, R. / Opacki, M. (2018). Recurrent strings in corpus-based pedagogical research: A reappraisal of the field. Glottodidactica, 45 (2), 134-149. DOI: 10.14746/ gl.2018.45.2.07.

Hall, E. T. (1989). Beyond culture. New York: Anchor.

Hall, J. K. / Verplaetse, L. S. (2000). Second and foreign language learning through classroom interaction. London: Routledge.

Hsiu-Chih, S. (2008). The value of English picture story books. ELT Journal, 62 (1), 47-55.

Kourieos, S. (2014). The knowledge base of primary EFL teachers: Pre-service and in-service teachers' perceptions. Journal of Language Teaching and Research, 5 (2), 291-300.

Koymen, S. B. / Kyratzis, A. (2009). Format tying and the acquisition of syntax in toddlers' peer interactions. Annual Meeting of the Berkeley Linguistics Society, 35 (1), 202-210.

Krashen, S. D. (1981). Second language acquisition and second language learning. Oxford: Oxford University Press.

Lewis, M. / Gough, C. / Martínez, R. / Powell, M. / Marks, J. / Woolard, G. C. / Ribisch, K. H. (1997). Implementing the lexical approach: Putting theory into practice (vol. 3, no. 1, pp. 223-232). Hove: Language Teaching Publications.

Linse, C. (2007). Predictable books in the children's EFL classroom. ELT Journal, 61 (1), 46-54.

Mackey, A. (2006). Feedback, noticing and instructed second language learning. Applied Linguistics, 27 (3), 405-430. doi.org/10.1093/applin/ami051. 
Masoni, L. (2018). The role of authentic children's literature in primary EFL teacher training. In: Pixel (ed.), Proceedings of the 11th Innovation in language learning international conference (pp. 216-218). Firenze: FILOdiritto Editore.

Masoni, L. (2019). Tale, performance and culture in EFL storytelling with young learners: Stories meant to be told. Cambridge: Cambridge Scholars Publishing.

Mayo, M. D. P. G. / Lecumberri, M. L. G. (eds.) (2003). Age and the acquisition of English as a foreign language. Clevedon: Multilingual Matters.

Moore, L. (2011). Language socialization and repetition. The handbook of language socialization, 1, 209-226.

Mourão, S. (2016). Picturebooks in the primary EFL classroom: Authentic literature for an authentic response. CLELE Journal, 4 (1), 25-43.

Muñoz, C. (2006). The effects of age on foreign language learning: The BAF project. In: Muñoz, C. (ed.), Age and the rate of foreign language learning (pp. 1-40). Clevedon: Multilingual Matters.

Muñoz, C. (2014). Contrasting effects of starting age and input on the oral performance of foreign language learners. Applied Linguistics, 35 (4), 463-482.

Nesmith, S. M. (2011). Powerful reflections result from quality questions: The influence of posed questions on elementary preservice teachers field-based reflections. Research in the Schools, 18 (2), 26.

Rokita-Jaśkow, J. / Ellis, M. (eds.) (2019). Early instructed second language acquisition: Pathways to competence. Clevedon: Multilingual Matters.

Schieffelin, B. / Ochs, E. (1996). The microgenesis of competence: Methodology in language socialization. In: D. Slobin / J. Gerhardt / A. Kyratzis / G. Jiansheng (eds.), Social interaction, social context and language: Essays in honor of Sue Ervin-Tripp (pp. 251-286). Hillsdale, NJ: Lawrence Erlbaum Associates.

Schmitt, N. (ed.), (2004). Formulaic sequences: Acquisition, processing and use. Amsterdam: John Benjamins Publishing.

Schmitt, N. / Underwood, G. (2004). Exploring the processing of formulaic sequences through a self-paced reading task. In: N. Schmitt (ed.), Formulaic sequences: Acquisition, processing and use (pp. 173-189). Amsterdam: John Benjamins Publishing.

Torr, J. (2004). Talking about picture books: The influence of maternal education on four-yearold children's talk with mothers and pre-school teachers. Journal of Early Childhood Literacy, 4 (2), 181-210.

Vogt, P. / Coumans, H. (2003). Investigating social interaction strategies for bootstrapping lexicon development. Journal of Artificial Societies and Social Simulation, 6 (1).

Wray, A. (1999). Formulaic language in learners and native speakers. Language Teaching, 32 (4), 213-231.

Wray, A. (2000). Formulaic sequences in second language teaching: principle and practice. Applied Linguistics, 21 (4), 463-489.

Wray, A. (2002). Formulaic language and the lexicon. Cambridge: Cambridge University Press.

Wray, A. (2008). The puzzle of language learning: From child's play to 'linguaphobia'. Language Teaching, 41 (2), 253-271.

Zukow-Goldring, P. (1996). Sensitive caregiving fosters the comprehension of speech: When gestures speak louder than words. Early Development and Parenting: An International Journal of Research and Practice, 5 (4), 195-211.

Received: 19.07.2019; revised: 23.10.2019 